\title{
Phenomena in the ionosphere-magnetosphere system induced by injection of powerful HF radio waves into nightside auroral ionosphere
}

\author{
N. F. Blagoveshchenskaya ${ }^{1}$, T. D. Borisova ${ }^{1}$, V. A. Kornienko ${ }^{1}$, B. Thidé ${ }^{2}$, M. T. Rietveld ${ }^{3}$, M. J. Kosch ${ }^{4}$, and \\ T. Bösinger ${ }^{5}$ \\ ${ }^{1}$ Arctic and Antarctic Research Institute, 38 Bering Str., St. Petersburg, 199397, Russia \\ ${ }^{2}$ Swedish Institute of Space Physics, Box 537, SE-75221, Uppsala, Sweden \\ ${ }^{3}$ EISCAT, N9027, Ramfjordmoen, Norway \\ ${ }^{4}$ Department of Communication Systems, Lancaster University, LA1 4YR, Lancaster, UK \\ ${ }^{5}$ Department of Physical Sciences, University of Oulu, P.O. Box 3000, FIN-90014, Oulu, Finland \\ Received: 30 September 2003 - Revised: 2 February 2004 - Accepted: 8 March 2004 - Published: 31 January 2005 \\ Part of Special Issue "Eleventh International EISCAT Workshop"
}

\begin{abstract}
Experimental results from three ionospheric HF pumping experiments in overdense $E$ or $F$ regions are summarized. The experiments were conducted by the use of the EISCAT HF Heating facility located near Troms $\varnothing$, Norway, allowing HF pumping the ionosphere in a near geomagnetic field-aligned direction. Distinctive features related to auroral activations in the course of the experiments are identified. Typical features observed in all experiments are the following: generation of scattered components in dynamic HF radio scatter Doppler spectra; strong increase of ion temperatures $T_{i}$ and local ionospheric electric field $E_{0}$; modification of the auroral arc and local spiral-like formation. However, some effects were observed only when the HF pump wave was reflected from the $F 2$ layer. Among them are the generation of intense field-aligned ion outflows, and a strong increase in the electron temperature $T_{e}$ with altitude. A possible scenario for the substorm triggering due to HF pumping into an auroral ionosphere is discussed. The authors present their interpretation of the data as follows. It is suggested that two populations of charged particles are at play. One of them is the runaway population of electrons and ions from the ionosphere caused by the effects of the powerful HF radio wave. The other is the population of electrons that precipitate from the magnetosphere. It is shown that the hydrodynamical equilibrium was disrupted due to the effects of the HF pumping. We estimate that the parallel electric field can reach values of the order of $30 \mathrm{mV} / \mathrm{m}$ during substorm triggering.
\end{abstract}

Key words. Ionosphere (active experiments; ionospheremagnetosphere interactions). Radio science (nonlinear phenomena).

Correspondence to: N. F. Blagoveshchenskaya

(nataly@aari.nw.ru)

\section{Introduction}

The significance of the general class of problems related to the manmade impact on the near-Earth space environment is evident from the results of well-known scientific programs such as TRIGGER, CRRES, CEDAR, and HAARP. Nevertheless, a number of crucial problems still remain unsolved, among them those associated with the modification of the ionosphere-magnetosphere coupling, the possible active role of the ionosphere in magnetospheric dynamics, and the response of the ionosphere-magnetosphere system to artificial perturbations. The controlled injection of powerful radio waves into space from purpose-built ground-based HF radio facilities has proved to be an excellent tool for studying the associated fundamental linear and nonlinear plasma processes and instabilities.

Considerable success has been achieved by the use of the EISCAT HF Heating facility located at auroral latitudes in Troms $\varnothing$, Norway (see, for example, Stubbe, 1996 (and references therein); Thidé et al., 1982; 1983; Rietveld et al., 1993, 2000; Robinson et al., 1998; Leyser, 2001; Leyser et al., 1989; Isham et al., 1990; 1999; Jones et al., 1984; Honary et al., 1999; Yeoman et al., 1997; Brändström et al., 1999; Eglitis et al., 1998; Blagoveshchenskaya et al., 1998b; Kosch et al., 2000).

It should be noted that in most HF pumping experiments performed hitherto, the plasma physics aspect has, for obvious reasons, dominated. However, taking the distinctive features and behavior of the auroral ionosphere into account, one would expect that the interaction between powerful HF radio waves and the auroral near-Earth space plasma can lead to the generation of specific modification effects not encountered at middle latitudes. As this article will show, this is indeed the case. 


\begin{tabular}{|l|l|l|l|}
\hline \multirow{2}{*}{ Operational modes } & \multicolumn{3}{l}{ Date of experiments } \\
\cline { 2 - 4 } & 16.02 .1996 & 17.02 .1996 & 2.10 .1998 \\
\hline Time, UT & $21-23$ & $20-22$ & $18-22$ \\
\hline Heater frequency, kHz & 4040 & 4040 & 4040 \\
\hline Reflection layer of HF pump wave & $E_{\mathrm{s}}$ & $E_{\mathrm{s}}$ & $F 2$ \\
\hline $\begin{array}{l}\text { Elevation of HF heater antenna } \\
\text { beam and its width, degrees }\end{array}$ & $84 \pm 9$ & $84 \pm 9$ & $78 \pm 6$ \\
\hline Gain of HF heater antenna, dBi & 19.9 & 19.9 & 22.35 \\
\hline ERP, MW & 53 & 53 & 188 \\
\hline Heating cycles, on/off, min & $+4 /-6$ & $+4 /-6$ & $+8 /-7$ \\
\hline Polarization & O-mode & O-mode & O-mode \\
\hline
\end{tabular}

Table 1. Operational modes of the EISCAT HF heating facility during experiments.

A large volume of work has been conducted by many scientists in understanding auroral substorm (see, for example, Akasofu, 1964; Kamide and Baumjohann, 1993; Kan, 1993; Foster, 1995; Lyons, 1996; Sergeev et al. 1996; Rostoker, 1999). Nonetheless, some problems still remaine unsolved, among them is the role of internal instabilities in the magnetosphere-ionosphere system leading to substorm triggering, a role of the auroral ionosphere in the substorm process. In this respect HF pumping experiments at auroral latitudes can provide answers to such problems. Experimental results from multi-instrument observations during Troms $\varnothing$ ionospheric modification experiments (Blagoveshchenskaya et al., 2001), make it evident that HF pumping into a sporadic auroral $E_{s}$ layer in the near field-aligned direction, can lead to a local auroral activation. The results obtained suggest that the energy source for such activations is the interaction between the solar wind and the magnetosphere.

Certain possibilities of HF pumping experiments related to the role of the ionospheric Alfvén resonator (IAR) in auroral phenomena were considered by Trakhtengerts et al. (2000). The theory developed allows for two types of triggering of the Alfvén vortex instability (AVI) in the IAR. The first is the generation of a resonant current in the dynamo region of the ionosphere. Its frequency and spatial scale across the magnetic field should coincide with the eigenfrequency and wavelength of the Alfvén vortex. The second type is based on a non-resonant local variation of the macroscopic electric field that can artificially turn on the AVI in the heated region (Trakhtengerts et al., 2000).

Excitation of Alfvén waves by modulated HF heating of the ionosphere, as well as the stimulated electron precipitation, was detected from the FAST satellite at an altitude of $2550 \mathrm{~km}$ above the Troms $\varnothing$ HF heater (Robinson et al., 2000).

In the present paper we invest our efforts on the further research of the ionospheric modification effects in the ionosphere-magnetosphere system caused by powerful HF radio waves. The main attention has been paid to the search for distinctive features related to the modification of the

ionosphere-magnetosphere coupling in the course of three Troms $\varnothing$ HF pumping experiments in the nightside auroral ionosphere. Experimental results from multi-instrument observations in the course of the experiment on 2 October 1998 are examined in detail. In this event, the HF pump wave was reflected from the $F 2$ layer in contrast to other experiments, when the powerful wave was reflected from a sporadic $E_{S}$ layer. The possible mechanisms responsible for the triggering of local auroral activations due to the effects of powerful HF radio waves are also discussed. The successful resolution of the problem concerning the HF pump wave impact on the ionosphere-magnetosphere coupling that could lead to the triggering of auroral activations requires the following: (1) fundamental studies in several fields and sub-fields, including plasma instabilities and nonlinear phenomena, on the one hand, and environmental magnetospheric physics, on the other; (2) the use of multi-instrument observations, new instruments, methods and observational methodology; (3) the performance of HF pumping experiments under specific geophysical conditions; (4) consistant, repeatable effects needed, that is more events showing the same effect.

Below we present our interpretation of the experimental data obtained in the course of HF ionospheric modification experiments in the nightside auroral ionosphere.

\section{Description of the HF pumping experiments}

The experiments reported here were carried out by the use of the EISCAT HF Heating facility (Rietveld et al., 1993) located near Troms $\emptyset$, Norway (geographical coordinates $69.6^{\circ} \mathrm{N}, 19.2^{\circ} \mathrm{E}$; magnetic dip angle $I=78^{\circ}$ ). We have summarized the experimental findings from such experiments performed in the nightside auroral ionosphere on 16 and 17 February 1996, and 2 October 1998. Notable is that in the course of the experiment on 16 February 1996, two auroral events occurred. A distinctive feature of the experiments is the tilt of the heater antenna beam to the south from zenith of $6^{\circ}$ or $12^{\circ}$, thus allowing HF pumping in a near field-aligned direction. The heating phased antenna array No. 2 was used in all experiments. The duration of the heater-on cycles was in all cases 4 or 8 minutes. The operational modes and the main parameters of the HF Heating facility for the experiments are given in Table 1.

The diagnostics of the ionospheric plasma based on effects due to HF pumping comprised multi-instrument observations from bistatic HF Doppler scatter (Blagoveshchenskaya et al., 1998a), the European Incoherent Scatter (EISCAT) UHF radar (Rishbeth and van Eyken, 1993), the digital all-sky imager DASI (Kosch et al., 1998), and the International Monitor for Auroral Geomagnetic Effects (IMAGE) magnetometer network in Scandinavia (Lühr et al., 1998). Additionally, bistatic scatter measurements of HF diagnostic signals were carried out on the London-Troms $\varnothing-$ St. Petersburg path at operational frequencies of 12,095 and $9410 \mathrm{kHz}$. The diagnostic $\mathrm{HF}$ transmitter is located near London $\left(52^{\circ} \mathrm{N}\right.$, $0^{\circ} \mathrm{E}$ ). The reception of the diagnostic waves, scattered from 
field-aligned irregularities (FAIs) above Troms $\varnothing$, was made with a Doppler spectral method in St. Petersburg $\left(60^{\circ} \mathrm{N}\right.$, $30.5^{\circ} \mathrm{E}$ ) at a great circle distance of $\sim 1200 \mathrm{~km}$ from Troms $\emptyset$. The condition for a bistatic scatter is given by

$\left(\boldsymbol{k}_{0} \cdot \boldsymbol{B}\right)=\left(\boldsymbol{k}_{S} \cdot \boldsymbol{B}\right)$,

where $\boldsymbol{k}_{0}$ and $\boldsymbol{k}_{\boldsymbol{S}}$ are the wave vectors of the incident and scattered wave respectively, and $\boldsymbol{B}$ is the vector of the Earth's magnetic field. A general view of the experiment geometry is shown in Fig. 1 of Blagoveshchenskaya et al. (2001). The simulation of bistatic scatter geometry for Troms $\varnothing$ HF pumping experiments is given by Borisova et al., (2002).

The onsets of the activations are the following: 21:21 and 22:41 UT on 16 February 1996; 20:33 UT on 17 February 1996, 19:30 UT on 2 October 1998. The first three activations were observed when the powerful HF radio waves were reflected from the sporadic $E_{S}$ layers, but the last activation occurred when the HF pump wave was reflected from the $F 2$ layer.

In addition to IMAGE magnetometer data, $A E, A U$, and $A L$ indices of the auroral activity, the $P C$ index from the near pole Vostok magnetic station (Troshichev et al., 1988), the $D_{s t}$ index of the magnetic activity, and parameters of the interplanetary magnetic field from the IMP-8 satellite have been used in the analysis of the auroral activations.

The results from the multi-instrument observations during Troms $\varnothing$ HF pumping experiments on 16 and 17 February 1996, when the powerful HF radio wave was reflected from the sporadic $E_{s}$ layer, were analyzed in detail by Blagoveshchenskaya et al. (2001). Experimental findings from the experiment of 2 October 1998, under the reflection of the HF pump wave from the $F 2$ layer of the ionosphere, are given in the next section.

\section{Observational results of 2 October 1998}

The experiment on 2 October 1998 was conducted during planetary-scale disturbed magnetic conditions. The values of the $D_{s t}$ index ranged between -56 and $-61 \mathrm{nT}$. The behavior of the interplanetary magnetic field (IMF) as measured from the IMP-8 satellite is shown in Fig. 1. The top panel in Fig. 1 displays variations of the $P C$ index from the near-pole Vostok station. One can see that the $B_{z}$ component of the IMF was steadily southward from 16:00 to 22:00 UT.

Ionograms from the Troms $\emptyset$ dynasonde showed that the critical frequencies of the $F 2$ layer increased from $4.1 \mathrm{MHz}$ at 19:00 UT to $5.5 \mathrm{MHz}$ at 19:30 UT. A sporadic $E_{s}$ layer is also identified in the ionograms, but its maximum frequency did not exceed 3.5 MHz. Therefore, in the experiment the HF pump wave $\left(f_{H}=4040 \mathrm{kHz}\right)$ was certainly reflected from the $F 2$ layer.

IMAGE magnetograms for the event on 2 October 1998 are presented in Fig. 2. It can be seen that a substorm activation occurred at 19:30 UT between the SOR $\left(70.54^{\circ} \mathrm{N}\right)$ and PEL $\left(66.9^{\circ} \mathrm{N}\right)$ magnetic stations. A westward electrojet appeared between the MAS $\left(69.46^{\circ} \mathrm{N}\right)$ and $\operatorname{MUO}\left(68.02^{\circ} \mathrm{N}\right)$
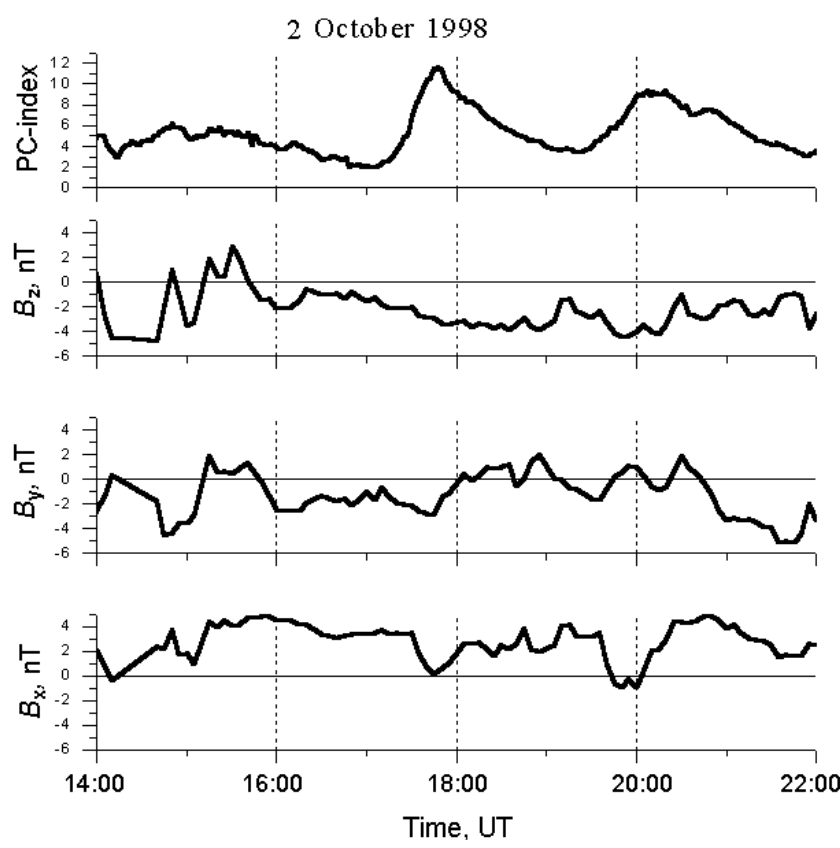

Fig. 1. The temporal behavior of the $P C$ index of the magnetic activity, $B_{z}, B_{y}$, and $B_{x}$ components of the interplanetary magnetic field on 2 October 1998.
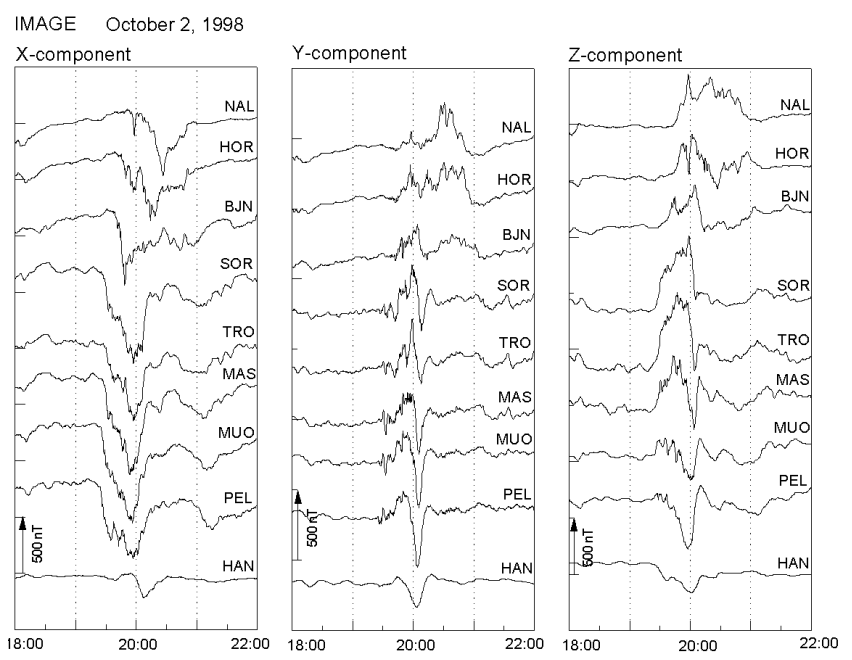

Fig. 2. The temporal behavior of the $X, Y$, and $Z$ components of the magnetic field variations on 2 October 1998. Data from the IMAGE magnetometers.

stations (reversal of $Z$ component from positive values at MAS to negative values at MUO station and maximum negative values of the $X$ component). This can be clearly seen more accurately from the $X-Z$ profiles obtained from the IMAGE magnetometers (see Fig. 3). Taking into account the tilt of the Troms $\varnothing$ heater antenna beam by $12^{\circ}$ to the south and the size of the heated patch in the $F 2$ layer, it is possible to conclude that the electrojet appeared in the southern part of the heated patch. The spatial position of the heated patch determined by the diagram of the heater antenna ( $3 \mathrm{~dB}$ contour) 


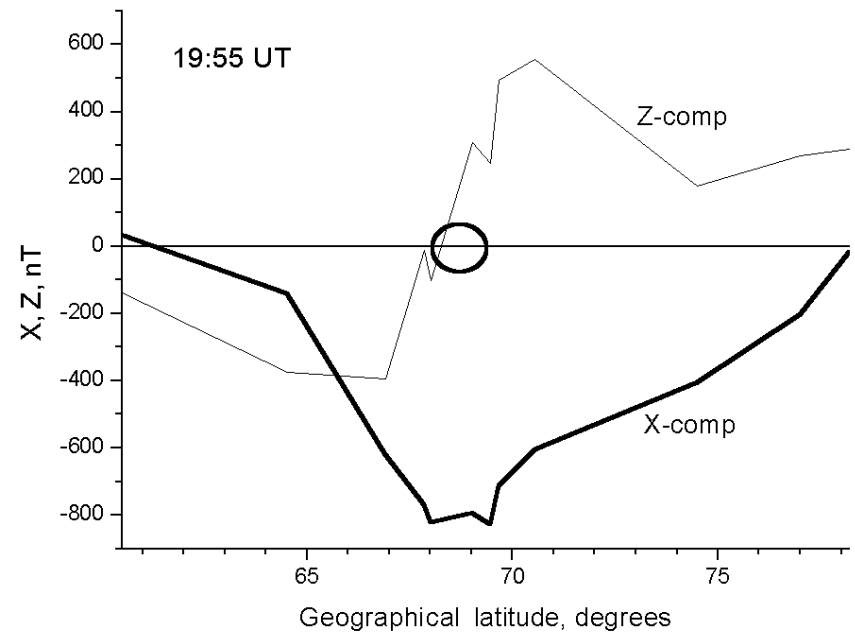

Fig. 3. $X-Z$ latitudinal profiles obtained from IMAGE magnetometers on 2 October 1998, at 19:55 UT. The spatial position of the heated patch at the altitude of $300 \mathrm{~km}$ is depicted by a circle.

is also shown in Fig. 3. In reality, from the CUTLASS HF radar measurements the spatial size of the heated patch can occupy a region significantly larger than the area contained within $3 \mathrm{~dB}$ contour (Robinson et al., 1998). It is interesting to note that a southward displacement preference was observed in other heater-induced phenomena during other HF pumping experiments, such as the radio-induced airglow (Kosch et al., 2000), and Langmuir turbulence (Isham et al., 1999) which may excite energetic electrons. The behavior of the $A E$ index describing the auroral activity as a whole also shows that the substorm occurred at 19:30 UT.

Figure 4 displays dynamic Doppler spectra of HF diagnostic signals obtained on 2 October 1998, on the LondonTroms $\varnothing-$ St. Petersburg path, for a radio scatter operational frequency of $12095 \mathrm{kHz}$ from 18:57 to 19:46 (Fig. 4a) and from 20:01 to 20:45 UT (Fig. 4b). One can see that during heater-on periods, 19:00-19:08 and 19:15-19:23 UT, the amplification of natural field-aligned irregularities can be recognized in the positive part of the Doppler sonogram. The heater turn-off at 19:23 UT is accompanied by the appearance of continuous noise-like spectral broadening. Then the burst-like noise enhancement in the dynamic Doppler spectra over a frequency range up to $20 \mathrm{~Hz}$ starts at about 19:27 UT (see Fig. 4a), i.e. 4 min after the Troms $\varnothing$ heater was turned off at 19:23 UT. It should be noted that the eigenperiod for the Tromsø magnetic flux tube is about 4 min (the Alfvén wave travel time to the magnetic conjugate ionosphere in the Southern Hemisphere and back, along magnetic field line). One might expect that an HF heater turn-off launches an Alfvén wave and leads to the reverberative echo effect in the HF scattered signals, which should manifest itself about 4 min later. This effect was discovered by Yampolski (1989) in SURA heating experiments.

What is the nature of the continuous and burst-like noise enhancements observed from HF Doppler measurements? We have analyzed the magnetic pulsation data recorded near

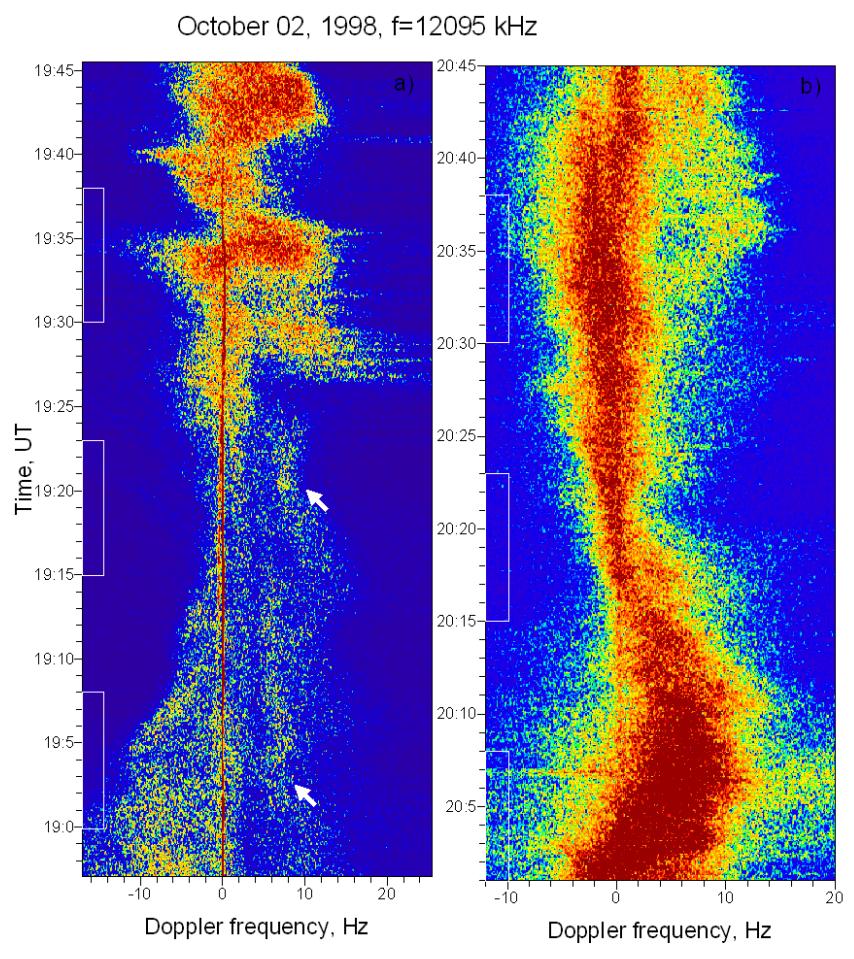

Fig. 4. Dynamic Doppler spectra of HF diagnostic signals on the London-Troms $\varnothing-$ St. Petersburg path on 2 October 1998, at the frequency 12,095 kHz: (a) 18:57-19:46 UT; (b) 20:01-20:45 UT. The direct signals propagating from the transmitter to the receiver along a great circle path correspond to zero Doppler shifts. The intervals when the Troms $\emptyset$ HF heating facility was turned on are marked by bars on the time axis. Arrows on the Doppler sonogram correspond to the signals scattered from the heater-enhanced natural field-aligned irregularities.

Troms $\varnothing$ at Kilpisjarvi (geographical coordinates $69.02^{\circ} \mathrm{N}$, $20.79^{\circ} \mathrm{E}$ ). By way of illustration Fig. 5 shows the temporal behavior of $H, D$, and $Z$ components of the magnetic field variations with 0.1-s temporal resolution and their sonogram (dynamic frequency spectra) in the frequency band of $5 \mathrm{~Hz}$ on 2 October 1998, from 19:00 to 19:40 UT. One can see the appearance of continuous pulsations in the frequency range up to $0.8 \mathrm{~Hz}$ from 19:23 UT (HF heater turn-off), which can be associated with the Pil short-period irregular magnetic pulsations of the PiC type. Thereafter, against this background the well-defined burst-like signals at frequencies up to $2.4 \mathrm{~Hz}$ are recognized from the sonogram. In accordance with classification of magnetic pulsations, these signals are identified as PiB magnetic pulsations. It should be pointed out that $\mathrm{PiC}$ and $\mathrm{PiB}$ magnetic pulsations are observed in all components $(H, D, Z)$ of the magnetic field. The comparison between HF Doppler scatter and magnetic pulsation data shows clearly the following. Features in the dynamic Doppler spectra of HF diagnostic signals, such as continuous and burst-like noise enhancements, may be attributed to $\mathrm{PiC}$ and $\mathrm{PiB}$ magnetic pulsations, correspondingly. In this respect it is significant that $\mathrm{PiB}$ pulsations correspond to the trapping of Alfvén wave energy in the ionospheric Alfvén 

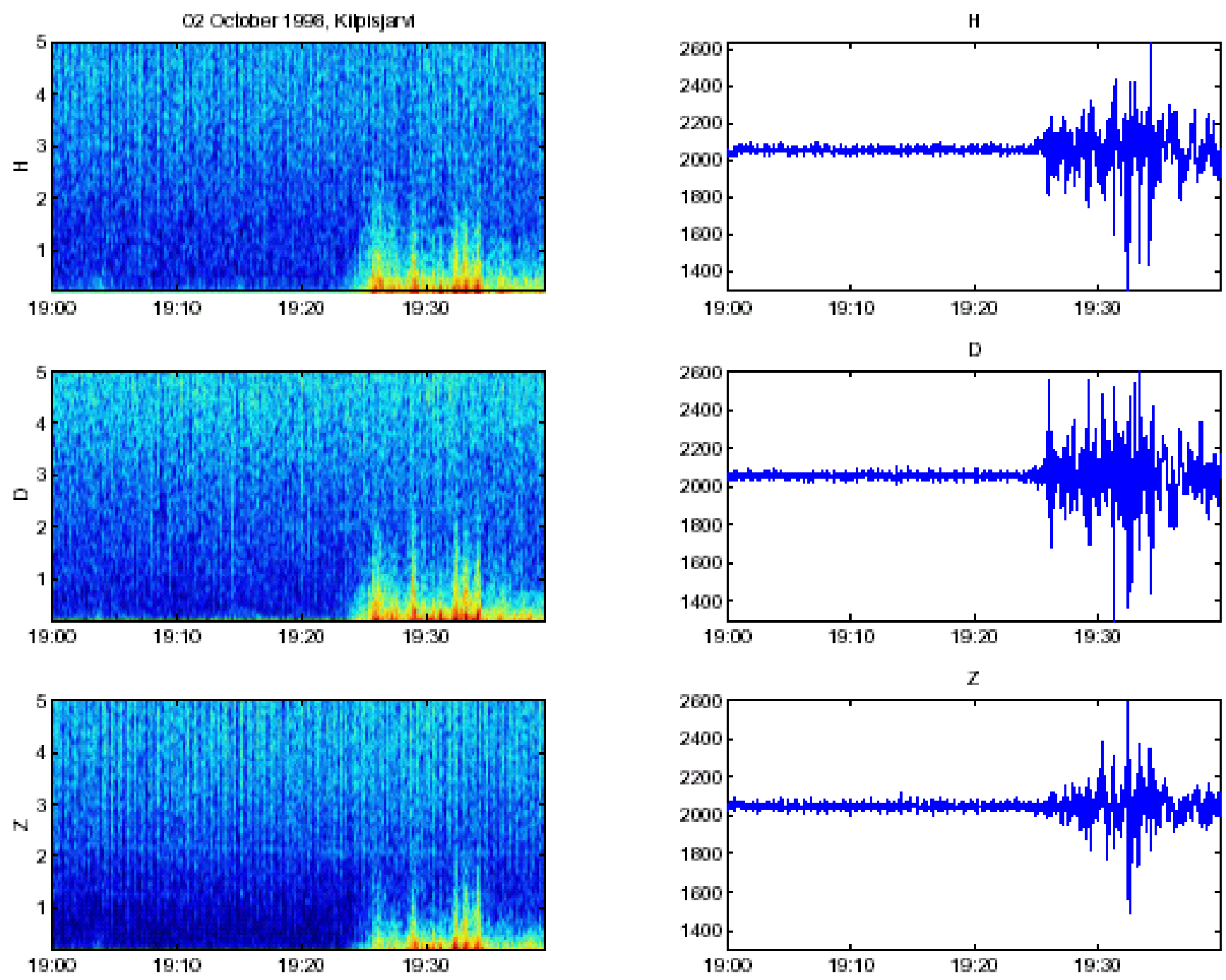

Fig. 5. $H, D$, and $Z$ components of magnetic pulsations recorded at Kilpisjarvi on 2 October 1998, and their sonograms (dynamic frequency spectra) in the frequency range from 0.2 to $5 \mathrm{~Hz}$.

resonator, IAR (Lysak and Song, 1998) or, in other words, to the generation of Alfvén vortices (short-scale oblique Alfvén waves) captured in the IAR (Trakhtengerts and Feldstein, 1991; Trakhtengerts et al., 2000). Recall that the IAR eigenfrequencies lie within the range $0.1-10 \mathrm{~Hz}$; they manifest themselves in the spectra of magnetic pulsations, as well as in the electromagnetic noise (Belyaev et al., 1999; Trakhtengerts et al., 2000). Therefore, there are reasons to assume that the observed electromagnetic noise, and $\mathrm{PiC}$ and $\mathrm{PiB}$ magnetic pulsations can be the manifestation of an excitation of the Alfvén vortices trapped in the ionospheric Alfvén resonator.

The other distinctive feature in the dynamic Doppler spectra of the scattered HF signals is the generation of an intense wave process with periods of 7-8 min. It started at 19:30 UT after the heater was turned on. The observed ionospheric wave disturbance is likely be to the signature of short-period atmospheric gravity waves, AGWs (Hunsucker, 1982). It is conceivable that an AGW can be launched by strong heaterenhanced electric fields via Joule heating and an indication of this has been observed in Arecibo (Thidé et al., 1989). Thereafter, the ionospheric wave process which takes place is not dependent on whether the Troms $\varnothing$ heater is turned on or off. At substorm maximum (about 20:00 UT) a large-scale ionospheric wave disturbance was generated above Troms $\varnothing$. It was observed throughout the recovery phase of the substorm. Its period was more than 45 min (see Fig. 4b). Similar wave disturbances are usually considered typical signatures of intense magnetospheric substorms and storms.

Interesting features in the ionospheric plasma parameters were observed by the EISCAT UHF incoherent scatter radar at Troms $\varnothing$, pointing in the magnetic field-aligned direction $\left(77^{\circ}\right)$. Figure 6 presents temporal variations of the electron density $N_{e}$, ion and electron temperatures $\left(T_{i}\right.$ and $\left.T_{e}\right)$, the ratio of $T_{e} / T_{i}$, and ion velocities $V_{i}$ obtained on 2 October 1998, from 18:57 to 20:10 UT at altitudes of 300,430 , and 

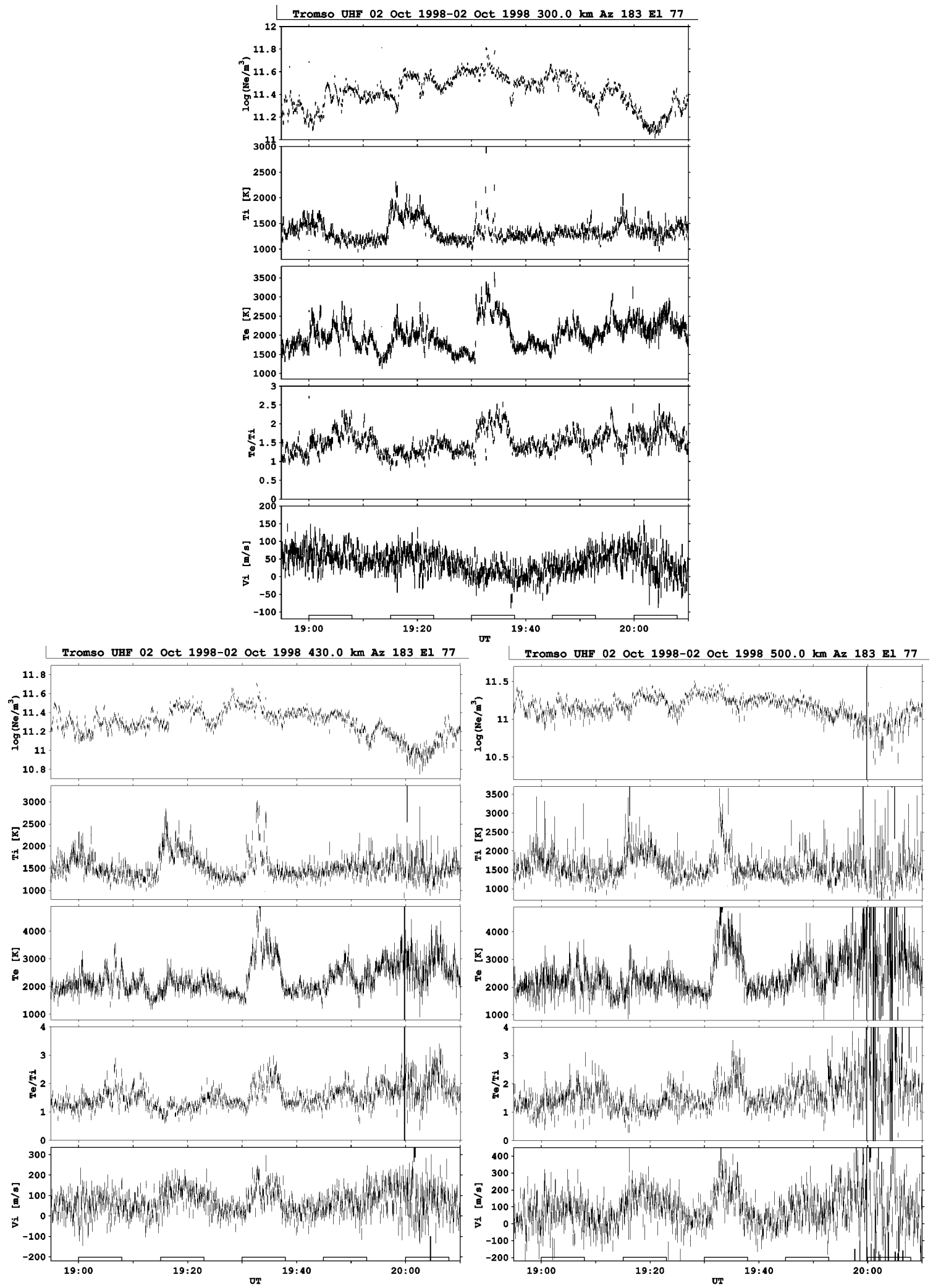

Fig. 6. The temporal behavior of the electron density $N_{e}$, ion temperature $T_{i}$, electron temperature $T_{e}$, the ratio of the $T_{e} / T_{i}$, and ion velocities $V_{i}$ as observed with the Troms $\emptyset$ EISCAT UHF incoherent scatter radar in the field-aligned direction on 2 October 1998, from 18:56 to 20:10 UT at altitudes of 300,430 , and $500 \mathrm{~km}$. EISCAT UHF radar data are obtained by using the long-pulse and analyzed with 20 -s integration time. The intervals when the Troms $\emptyset$ HF heating facility was operated are marked by bars on the time axis. The Troms $\emptyset$ HF heating facility was operated with a 8-min on, 7-min off pump cycle (4-min 50\% full power, 4-min 100\% power then 7-min off). 


\begin{tabular}{|c|c|c|c|c|c|c|}
\hline Parameter & $\begin{array}{c}\text { Time, } \\
\text { UT }\end{array}$ & $\begin{array}{c}\text { Mean, } \\
\text { K }\end{array}$ & $\begin{array}{c}\text { Standard } \\
\text { deviation, } \\
\mathrm{K}\end{array}$ & $\begin{array}{l}\text { Standard } \\
\text { error of the } \\
\text { mean, } \mathrm{K}\end{array}$ & $\begin{array}{l}\text { Minimum } \\
\text { value, } \\
\mathrm{K}\end{array}$ & $\begin{array}{l}\text { Maximum } \\
\text { value, } \\
\mathrm{K}\end{array}$ \\
\hline \multirow{5}{*}{$\begin{array}{l}T_{e} \text { at } \\
315 \mathrm{~km}\end{array}$} & $19.00-19.08$ (on) & 2144 & 309 & 45 & 1514 & 2738 \\
\hline & $19.15-19.23$ (on) & 2052 & 215 & 31 & 1596 & 2569 \\
\hline & $19.30-19.38$ (on) & 2511 & 538 & 78 & 1345 & 3702 \\
\hline & $19.08-19.15$ (off) & 1711 & 254 & 39 & 1305 & 2320 \\
\hline & $19.23-19.30$ (off) & 1644 & 196 & 31 & 1344 & 2055 \\
\hline \multirow{5}{*}{$\begin{array}{l}T_{e} \text { at } \\
517 \mathrm{~km}\end{array}$} & $19.00-19.08$ (on) & 2380 & 463 & 68 & 1682 & 3615 \\
\hline & $19.15-19.23$ (on) & 2252 & 484 & 72 & 1367 & 4763 \\
\hline & $19.30-19.38$ (on) & 3270 & 1148 & 169 & 1515 & 6119 \\
\hline & $19.08-19.15$ (off) & 2048 & 366 & 57 & 1427 & 2699 \\
\hline & $19.23-19.30$ (off) & 2060 & 309 & 49 & 1553 & 2795 \\
\hline \multirow{5}{*}{$\begin{array}{l}T_{i} \text { at } \\
315 \mathrm{~km}\end{array}$} & $19.00-19.08$ (on) & 1366 & 162 & 23 & 1087 & 1715 \\
\hline & 19.15-19.23 (on) & 1777 & 224 & 32 & 1314 & 2394 \\
\hline & $19.30-19.38$ (on) & 1434 & 293 & 42 & 1098 & 2884 \\
\hline & $19.08-19.15$ (off) & 1212 & 130 & 20 & 1019 & 1748 \\
\hline & $19.23-19.30$ (off) & 1228 & 92 & 14 & 1021 & 1514 \\
\hline \multirow{5}{*}{$\begin{array}{l}T_{i} \text { at } \\
517 \mathrm{~km}\end{array}$} & $19.00-19.08$ (on) & 1552 & 381 & 56 & 737 & 2655 \\
\hline & $19.15-19.23$ (on) & 1855 & 360 & 53 & 1010 & 2734 \\
\hline & $19.30-19.38$ (on) & 1789 & 583 & 86 & 663 & 3691 \\
\hline & $19.08-19.15$ (off) & 1395 & 251 & 39 & 829 & 1830 \\
\hline & $19.23-19.30$ (off) & 1396 & 186 & 29 & 1080 & 1833 \\
\hline
\end{tabular}

Table 2. The mean values, the standard deviations, the standard errors of the means, the minimum and maximum values of the $T_{e}$ and $T_{i}$ at altitudes of 315 and $517 \mathrm{~km}$ calculated during the heater-on and heater-off periods on 2 October 1998.

$500 \mathrm{~km}$. Note that the EISCAT UHF radar was probing in the geomagnetic field-aligned direction. From Fig. 6 one can see very strong $T_{e}$ enhancements, closely related to the consecutive heater-on periods from 19:00-19:08, 19:15-19:23, 19:30-19:38, and 19:45-19:53 UT. Enhancements in $T_{e}$ were observed over a wide altitude range from 200 to $600 \mathrm{~km}$ (the upper altitude limit of the EISCAT UHF radar measurements in the experiment). It is common knowledge that HF pumpinduced electron heating, as well as the excitation of artificial field-aligned irregularities (AFAI) and the anomalous absorption, is a phenomenon related to the upper hybrid wave. It is generated at the vicinity of the upper hybrid resonance (UHR) altitude, where the heater frequency $f_{H}$ is equal to the local upper hybrid frequency, $f_{H}^{2}=f_{0}^{2}+f_{c e}^{2}\left(f_{0}\right.$ is the local plasma frequency and $f_{c e}$ is the electron gyrofrequency). The UHR height is several kilometers below from the reflection level of the HF pump wave. In the course of the experiment on 2 October 1998 very strong electron temperature enhancements were observed in a wide altitude range well above the reflection level of the HF waves. Enhancements in $T_{e}$ were accompanied by strong $T_{i}$ increases along with positive (upward) ion velocities from altitudes above $350 \mathrm{~km}$.

The variations in $T_{e}$ and $T_{i}$ during the heater on and off cycles are stronger under disturbed magnetic conditions than under quiet conditions. There is a good reason to compare the mean values of $T_{e}$ and $T_{i}$ during heater-on and heateroff periods. For this purpose 10-s resolution data from the EISCAT UHF radar measurements at altitudes of $315 \mathrm{~km}$ (near the reflection level of the HF pump wave) and $517 \mathrm{~km}$, that is well above the reflection altitude of the powerful HF radio wave, were employed. Calculation results of the means, the standard deviations, and the standard errors of the means are summarized in Table 2, where one can see that the means and standard deviations of the $T_{e}$ and $T_{i}$ in all heateron cycles exceed the same parameters calculated in heater-off periods at both altitudes of 315 and $517 \mathrm{~km}$.

The positive $V_{i}$, indicative of the generation of upward ion flows, reached their maximum values (about $400 \mathrm{~m} / \mathrm{s}$ at the height of $500 \mathrm{~km}$ ) in the heater-on period from 19:30-19:38 UT, corresponding in time to the substorm onset. Note that the HF pump waves modify significantly the ionospheric plasma, even after the substorm onset. During the heater-on period, from 19:45 to 19:53 UT there are the $T_{e}$ enhancements, as well as a generation of heater-induced upward ion flow.

Large electron temperature enhancements (a doubling) produced by strong HF pump waves during winter night hours were observed at Arecibo (Djuth et al., 1987). These $T_{e}$ enhancements were measured in a narrow altitude range near the upper hybrid resonance (UHR) height. Recent experimental results from Troms $\emptyset$ HF pumping experiments in the nightside ionospheric $F$-region during quiet magnetic conditions (Rietveld et al., 2003) clearly demonstrate not only extremely strong $T_{e}$ enhancements in a wide altitude range, but also increases in the ion temperatures of about one hundred degrees and the generation of upward ion flows 


\begin{tabular}{|l|c|c|c|c|}
\hline \multirow{2}{*}{$\begin{array}{c}\text { Geophysical } \\
\text { conditions }\end{array}$} & \multicolumn{4}{|c|}{ Auroral activation onsets, date and time, UT } \\
\cline { 2 - 5 } & \multicolumn{2}{|c|}{16.02 .96} & 17.02 .96 & 2.10 .98 \\
\cline { 2 - 5 } & 21.21 & 22.41 & 20.33 & 19.30 \\
\hline $\begin{array}{l}B_{\mathrm{z}} \text { component of } \\
\text { IMF, nT }\end{array}$ & -1.5 & -1.5 & 1.0 & -4.0 \\
\hline$D_{\text {st }}$ index, nT & 3 & 1 & -4 & -59 \\
\hline$K_{\mathrm{p}}$ index & $3 \mathrm{o}$ & $3 \mathrm{o}$ & $2 \mathrm{o}$ & $5+$ \\
\hline$\Sigma K_{\mathrm{p}}$ & $17+$ & $17+$ & $15+$ & $33+$ \\
\hline $\begin{array}{l}\text { Orientation of the } \\
\text { background electric } \\
\text { field }\end{array}$ & $\begin{array}{c}\text { north- } \\
\text { south }\end{array}$ & $\begin{array}{c}\text { north- } \\
\text { south }\end{array}$ & north-south & $\begin{array}{c}\text { north- } \\
\text { south }\end{array}$ \\
\hline
\end{tabular}

Table 3. Background geophysical conditions in the course of the HF pumping experiments.

along magnetic field-aligned direction as well. Moreover, the strongest pumping effects occurred when the powerful HF radio wave is beamed along magnetic field line.

Even though the HF pumping effects observed in the experiment on 2 October 1998 resemble the effects observed by Rietveld et al. (2003), there is a clear distinction between them. On 2 October 1998 strong $T_{e}$ increases with altitude are measured, especially at the beginning of a heater-on period corresponding to the substorm onset, when $T_{e}=2800 \mathrm{~K}$ at the altitude of $h=300$; they reach the values of $T_{e}=5000 \mathrm{~K}$ at $h=500 \mathrm{~km}$.

The $T_{i}$ enhancements most pronounced in the heater-on periods from 19:15-19:23 and 19:30-19:38 UT may be attributed to the increase in the ionospheric electric field. In this respect it should be mentioned that a very strong $T_{i}$ increase, accompanied by drastic enhancements in the ionospheric electric field, was observed during the triggering of the local auroral activations when HF pumping was made into the nightside auroral $E$ region (Blagoveshchenskaya et al., 2001). A substantial doubling of the southward-pointing convection electric field caused by HF heating was also measured from a sounding rocket inside of the Arecibo HF heater beam (Peria and Kelley, 2001).

The origin of heater-induced upward ion flows in HF ionospheric modification experiments is not clear. Ion upflow events from EISCAT UHF radar measurements, observed naturally in the $F$ region, can be devided into two types as described by Wahlund et al. (1992). Type I events are related to the strong perpendicular electric field $E_{0}$, enhanced $T_{i}$ due to frictional heating and low electron densities (thermal plasma outflow). Type II upflows are associated with active auroral conditions and increased electron temperatures $T_{e}$. They may be related to enhanced parallel electric field $E_{\|}$along magnetic field-aligned direction caused by anomalous resistivity due to ion acoustic turbulence. Forme and Fontaine (1999) have found that ion acoustic turbulence can greatly increase the electron temperature, leading to the upward ion acceleration by enhanced field-parallel electric field. In the course of the experiment on 2 October 1998, carried out during dis- turbed background conditions, the occurrence of upward ion flows was observed in conjunction with greatly increased both $T_{e}$ and $T_{i}$. Moreover, the appearance of ion upflows was accompanied by heater-enhanced ion lines after turn-on of the Troms $\varnothing$ HF heater, which is indicative of ion acoustic turbulence. Heater-enhanced ion lines were measured at 19:00:05, 19:15:05, and 19:30:05 at altitudes of 303, 267, and $248 \mathrm{~km}$, correspondingly. Heater-enhanced ion lines are observed at altitudes in the close vicinity of the reflection height of the powerful HF radio wave. One may speculate that the generation of the heater-driven upward ion flows may be related to the parallel electric field. Nonetheless, we do not exclude the other ion acceleration mechanisms which can operate in the HF modified auroral ionosphere.

Summarizing the experimental findings from the multiinstrument observations in the course of the Troms $\varnothing$ HF pumping experiment on 2 October 1998, one can distinguish the following features related to the auroral activation: (1) amplification of natural field-aligned irregularities during heater-on periods; (2) possible appearance of the reverberative echo effect in the HF scattered signals that manifests itself about 4 min (eigenfrequency of the Troms $\varnothing L$-shell) after the HF heater was turned off; (3) burst-like electromagnetic noise enhancements in the dynamic Doppler spectra of HF scattered signals accompanied by $\mathrm{PiB}$ magnetic pulsations that can be associated with the trapping of Alfvén wave energy in the ionospheric Alfvén resonator; (4) strong $T_{e}$ and $T_{i}$ enhancements in a wide altitude range driven by HF pumping; (5) generation of the heater-induced intense upward ion flows along the magnetic field lines; (6) strong $T_{e}$ increases with altitude during heater-on period corresponding to the substorm onset; (7) substorm onset in the southern part of the heated patch under a steady southward $B_{z}$ component of the IMF.

\section{Distinctive features related to the auroral activations}

In this section we summarize and compare the distinctive features related to auroral activations from Troms $\varnothing$ HF pumping experiments in the nightside auroral ionosphere under the reflection of HF pump wave from $F 2$ layer (Sect. 3), as well as from the sporadic $E_{S}$ layer (Blagoveshchenskaya et al., 2001).

First of all, there is a need to examine the background geophysical conditions during the HF pumping experiments. From Table 3 one can see that the experiments on 16 and 17 February 1996 were conducted under slightly disturbed magnetic conditions. The values of the $K_{p}$ index were about $K_{p}=2-3$ and $15 \leq \Sigma K_{p} \leq 18$. During the experiment on 2 October 1998, the magnetic conditions were disturbed, and values of the $K_{p}$ index were $K_{p}=5$ and $\Sigma K_{p}=33$.

The distinctive features related to four auroral activations from multi-instrument observations are summarized in Table 4. Let us consider these characteristics in more detail. The generation of wide band spectral features in the Doppler radio scattering data was observed in all 


\begin{tabular}{|c|c|c|c|c|}
\hline \multirow{3}{*}{$\begin{array}{l}\text { Distinctive features from different } \\
\text { observational methods }\end{array}$} & \multicolumn{4}{|c|}{ Auroral activations onsets, date and time, UT } \\
\hline & \multicolumn{2}{|c|}{16.02 .96} & \multirow{2}{*}{$\begin{array}{c}17.02 .96 \\
20.33\end{array}$} & \multirow{2}{*}{$\begin{array}{c}2.10 .98 \\
19.30\end{array}$} \\
\hline & 21.21 & 22.41 & & \\
\hline $\begin{array}{l}\text { Generation of spectral broadening } \\
\text { components }\end{array}$ & + & + & + & + \\
\hline Increases of $T_{i}$ and local $E_{0}$ & + & + & + & + \\
\hline Modification of the auroral arc & + & + & + & no meas. \\
\hline $\begin{array}{l}\text { Strong } T_{e} \text { enhancements with } \\
\text { altitude }\end{array}$ & - & - & - & + \\
\hline Generation of upward ion flows & - & - & - & + \\
\hline $\begin{array}{l}\text { Auroral activations above the } \\
\text { artificially disturbed ionospheric } \\
\text { region (ADIR) }\end{array}$ & + & + & + & + \\
\hline $\begin{array}{l}\text { Magnetic disturbances to the } \\
\text { northward direction after } \\
\text { activation above ADIR }\end{array}$ & + & + & + & + \\
\hline
\end{tabular}

Table 4. Distinctive features related to auroral activations in course of the experiments.

experiments. As it was shown in Sect. 3, there is the association of electromagnetic noise enhancements from HF Doppler observations with Pi1 magnetic pulsations. It can be indicative of ionospheric Alfvén resonator effects (Trakhtengerts et al., 2000). What are the possible mechanisms needed for the excitation of ionospheric Alfvén resonator effects due to unmodulated HF heating of the Earth's ionosphere? Clearly, to answer this, new theoretical approaches and special-oriented experiments are needed.

The strong increases of the ion temperatures, as well as the local ionospheric electric fields, observed in all events analyzed can be explained in terms of the theory for nonresonant local variations of the macroscopic electric field developed by Trakhtengerts et al. (2000). Peria and Kelley (2001) have proposed the ponderomotive force and temperature gradients, both of which are ubiquitous during HF heating, as the candidate mechanisms for the heater-induced ionospheric electric field.

Modification of the auroral arc and local spiral-like formation is seen in all experiments under reflection of the HF pump wave from the sporadic $E_{s}$ layer, see Plates 1 and 2 of Blagoveshchenskaya et al. (2001). Unfortunately, the optical observations were not carried out when the powerful HF radio wave was reflected from $F 2$ layer (experiment on 2 October 1998).

Nevertheless, there are some effects observed only on 2 October 1998, when the $F 2$ layer was overdense, during disturbed magnetic conditions (see Tables 3 and 4). Only the latter experiment show evidence for a generation of intense heater-induced upward ion flows (ion velocities up to $400 \mathrm{~m} / \mathrm{s}$ at the altitude of $500 \mathrm{~km}$ ), strong enhancement of the electron temperature $T_{e}$ along the magnetic field-aligned direction in a wide altitude range from 200 to $600 \mathrm{~km}$ (upper limit of the EISCAT UHF radar measurements during the experiment), and strong $T_{e}$ increases with altitude during the heater-on

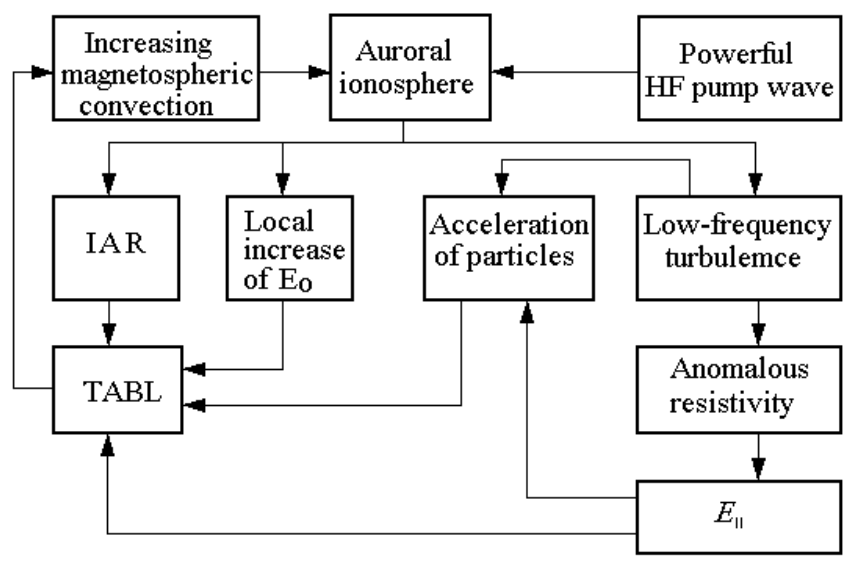

Fig. 7. A possible scheme for the triggering of local auroral activations due to HF pumping into nightside auroral ionosphere. IAR is the ionospheric Alfvén resonator; TABL is the turbulent Alfvén boundary layer.

period, corresponding to the substorm onset. Furthermore, in the latter experiment, auroral activation occurred in a localized latitudinal region that extends to larger scales with a latitudinal width of $3^{\circ}$ (see Sect. 3) as compared to the activations on 16 and 17 February 1996 (latitudinal width of $1^{\circ}$ ) observed by Blagoveshchenskaya et al. (2001).

Strong electron temperature enhancements and a southward shift of the strongly heated region can apparently be explained by the theory of self-focusing on striations of the HF pump wave developed by Gurevich et al. (2001). This theory describes a formation of a large-scale nonlinear structure along the magnetic field line, consisting of a number of bunches of striations (solitons). It is interesting to mention that in experiments at Arecibo, direct measurements of striations were performed by Kelly et al. (1995). The nonlinear structuring is also manifested in observations (Kelly et al., 1995; Franz et al., 1999). It should be pointed out that the generation of striations and the large-scale nonlinear structuring at Arecibo is much more difficult than at high latitudes (Gurevich et al., 1999).

It was shown by Bernhardt et al. (1988) that HF pumpinduced ohmic and anomalous heating increases the electron temperature and the plasma pressure in the heated patch, which, in turn, accelerates the plasma along the magnetic field lines. Upward ion flows were predicted by Vas'kov et al. (1993) for the Arecibo case based on a model with a solitary ion-acoustic compression wave propagating along the field-aligned direction. Mingaleva and Mingalev (1997) performed modelling for conditions of the high-latitudinal ionosphere.

In spite of numerous radar and satellite observations of ion upflows at auroral latitudes, see, for example, Foster et al. (1998), the initial mechanisms that preheats the ionospheric ions, which then propagate upward along magnetic field lines due to the parallel electric field and mirror force, are widely debated. Postulated mechanisms include 

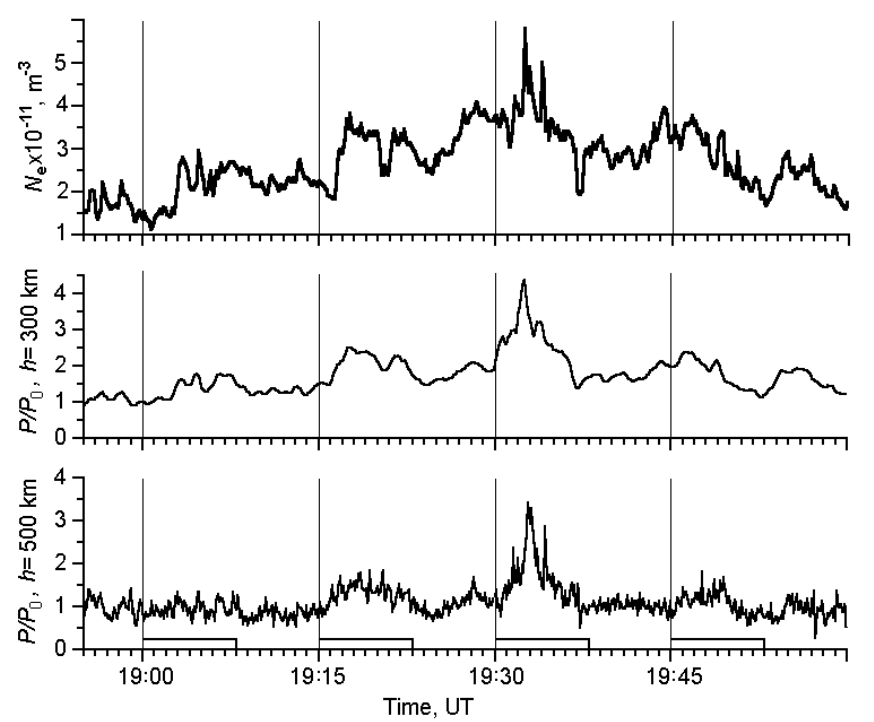

Fig. 8. The temporal behavior of the electron density $N_{e}$ at the altitude of $300 \mathrm{~km}$ from the EISCAT UHF radar measurements, relative values of partial pressure $P / P_{0}$ at the altitudes of 300 and $500 \mathrm{~km}$ in the course of the Troms $\varnothing$ HF pumping experiments on 2 October 1998, from 18:55 to 20:00 UT. The intervals when the Troms $\varnothing$ heater was turned on are marked by bars on the time axis.

ion frictional heating due to the perpendicular electric field (Baron and Wand, 1983), lower hybrid waves, ion cyclotron waves, and solitons (Forme and Fontaine, 1999; Ogawa et al., 2000; Kovtyukh, 2001; Mälkki and Lundin, 1994), stochastic ion heating on short perpendicular wavelength electrostatic waves and structures (Stasiewicz et al., 2000). Note that multiple acceleration processes may be operative along magnetic field lines at different altitudes (Sagawa et al., 1991).

\section{Possible mechanisms for the triggering of auroral ac- tivations}

A possible scenario for the substorm triggering due to $\mathrm{HF}$ pumping into the nightside auroral ionosphere along magnetic field-aligned direction is illustrated by the scheme in Fig. 7.

The accumulation of the energy in the magnetospheric tail due to the solar wind-magnetosphere interaction is accompanied by an increase in the laminar magnetospheric convection. Thermal nonlinear interaction between powerful HF radio waves and the auroral ionospheric plasma leads to a local increase in the ionospheric electric field $E_{0}$ (Blagoveshchenskaya et al., 2001), the excitation of the ionospheric Alfvén resonator (IAR) and low-frequency turbulence. The enhanced currents lead to Alfvén wave trapping in the ionospheric Alfvén resonator, which is bounded from below by the heater-modified $E$ region and from above by the region of a sharp increase in the Alfvén velocities at altitudes up to one Earth radius (Trakhtengerts and Feldstein, 1991). Models predicting changes in the ionospheric conductivity and feedback instability in the magnetosphere-ionosphere system were developed by Lysak (1990, 1991), Trakhtengerts and Feldstein (1991), and Stasiewicz et al. (2000).

Heater-induced low-frequency turbulence leads to a fieldaligned potential drop in the magnetic flux tube, anomalous resistivity, and the development of a parallel electric field $E_{||}$. It was found by Haerendel (1990) that the parallel electric field may be responsible for the decoupling of the magnetospheric convection from the ionosphere. The enhanced ionospheric electric field, the parallel electric field, the turbulent plasma heating, and the acceleration of runaway charged particles are possible mechanisms for the Alfvén wave dissipation in the ionospheric Alfvén resonator which, in turn, leads to the excitation of the turbulent Alfvén boundary layer (TABL) or, in other words, Alfvén vortex instability (AVI) in the IAR (Trakhtengerts and Feldstein, 1991; Trakhtengerts et al., 2000). It may serve as a trigger of the auroral activation.

It is of interest to estimate possible changes in the ionospheric electric field $E_{0}$ and the parallel electric field $E_{\|}$ during HF pumping experiments at high latitudes. It has been predicted by Trakhtengerts et al. (2000) that a strong local increase of $E_{0}$ can occur near the "nose" of the heatermodified ionospheric region, if the disturbed region is elongated along the background electric field $E_{0}$ and the disturbance is large. In this case the amplitude of the electric field $E_{m}$ near the nose of the heater-modified ionospheric region is of the order of $E_{m} \approx 3.5 E_{0}$ (Trakhtengerts et al., 2000), which is close to that which we observed from the EISCAT UHF radar measurements in HF heating experiments (Blagoveshchenskaya et al., 2001).

Assuming charge neutrality, $J_{z}$ can be estimated by (Kamide and Baumjohann, 1993)

$J_{z}=\Delta n e V_{\|}$,

where $\Delta n$ is the change in the electron density, $V_{\|}$is the field-aligned current velocity, $e$ is the electron charge.

Figure 8 displays the temporal behavior of the electron density $N_{e}$ at an altitude of $300 \mathrm{~km}$, as measured by the EISCAT UHF radar during the HF pumping experiment on 2 October 1998, as well as the calculated values of the relative plasma partial pressure $P / P_{0}$ at altitudes of 300 and $500 \mathrm{~km}$. The condition of the hydrodynamical equilibrium is fulfilled when the partial pressure is kept constant, $P=N_{e}\left(T_{e}+T_{i}\right)=$ const.

Therefore, the values of $P / P_{0}$ can be written as (Gurevich, 1978)

$P / P_{0}=\frac{N_{e}\left(T_{e}+T_{i}\right)}{N_{e 0}\left(T_{e 0}+T_{i 0}\right)}$,

where $T_{e 0}, T_{i 0}$, and $N_{e 0}$ are the electron and ion temperatures, and the electron density before the HF heater is turned on; $T_{e}, T_{i}$, and $N_{e}$ are the same parameters in the course of the heater-on periods. From Fig. 8 one can see that the hydrodynamical equilibrium has been disrupted due to the effects of powerful HF radio waves. The strongest increase in the 
partial pressure takes place in the heating cycles at 19:1519:23 and 19:30-19:38 UT. Furthermore, heater-induced effects in the behavior of $P / P_{0}$ were observed at the altitudes of 300 and $500 \mathrm{~km}$ as well.

We speculate that there are two electron populations during heater-on periods. One of them is the downward fieldaligned current carrying heater-induced runaway electrons from the ionosphere. The other one is the electron precipitation from the magnetosphere carrying the background upward field-aligned current, responsible for the formation of the substorm current system (Boström, 1964; Kan, 1993; Haerendel, 1990; Kamide and Baumjohann, 1993; Rostoker, 1999). The presence of two electron populations in HF pumping experiments is confirmed by direct observations from the FAST satellite (Robinson et al., 2000). One might expect that the heater-induced runaway electron population may promote the development of current-driven instabilities which, in turn, leads to the decoupling of magnetospheric convection from the ionosphere. This corresponds to the onset of auroral activation.

The field-aligned current velocity $V_{\|}$can be obtained from the condition of a current convective instability growth (Ossakow and Chaturvedi, 1979)

$\frac{V_{\|}}{L_{N}} \geq \frac{\left(T_{e}+T_{i}\right) k_{\|}^{2}}{m v_{e}} \sqrt{\frac{M}{m} \frac{v_{i n}}{v_{e n}}}$,

where $m$ and $M, T_{e}$ and $T_{i}$ are the electron and ion masses and the temperatures, respectively; $v_{e n}$ and $v_{i n}$ are collision frequencies of electrons/ions with neutrals; $v_{e}=v_{e n}+v_{e i}$, where $v_{e i}$ is the Coulomb collision frequency; $L_{N}$ is a typical scale of the perpendicular plasma density gradient; $k_{\|}$is the field-aligned wave number of irregularities. For $V_{\|}$calculations, the $T_{e}$ and $T_{i}$ values were taken from the EISCAT UHF radar measurements. We assume that $L_{N}=1$. The collision frequencies $v_{e n}, v_{e i}$, and $v_{e}$ were calculated by taking into account the values of $T_{e}, N_{e}, N_{n}$, and $N_{i}$. Calculations of the neutral component $N_{n}$ on 2 October 1998 versus altitude and time were made by using MSIS-E-90 Model (http: //nssdc.gsfc.nasa.gov/space/model/models/msis.html). The field-aligned wave number of irregularities $k_{||}$is found, taking into account the ratio of field-aligned to cross-field scales $l_{\|} / l_{\perp} \sim 2 \cdot 10^{3}$ (Kagan and Frolov, 1996). In the course of our experiments, the bistatic HF Doppler radio scatter used the 12095 and $9410 \mathrm{kHz}$ carrier signals from London transmitters and therefore was sensitive to irregularities with spatial scales $l_{\perp} \approx 12-15 \mathrm{~m}$.

From expression (4) and with the use of the experimental values of $T_{e}=2500-3000 \mathrm{~K}$ and $T_{i}=1700-2500 \mathrm{~K}$ at the altitude of $300 \mathrm{~km}$ and $T_{e}=3200-5000 \mathrm{~K}$ and $T_{i}=2000-3500 \mathrm{~K}$ at the altitude of $500 \mathrm{~km}$, the field-aligned current velocity $V_{\|}$ is estimated to be in the range $2<V_{\|}<4 \mathrm{~km} \cdot \mathrm{s}^{-1}$ at $h=300 \mathrm{~km}$ and in the range $5<V_{\|}<15 \mathrm{~km} \cdot \mathrm{s}^{-1}$ at $h=500 \mathrm{~km}$.

Rough estimates of the parallel electric field $E_{\|}$can be made from the expression (Ginzburg, 1967)

$$
E_{\|} \sim \frac{m}{e} V_{\|} \sqrt{\omega^{2}+v_{e}^{2}} \sqrt{\frac{2 m}{M}},
$$

where $V_{\|}$is the field-aligned current velocity from Eq. (4), $\omega$ is the plasma frequency, and $m, M, e$, and $v_{e}$ are the same as in Eq. (4).

Setting $V_{\|}=2-4 \mathrm{~km} \cdot \mathrm{s}^{-1}$ at $h=300 \mathrm{~km}$ and $V_{||}=5-15 \mathrm{~km} \cdot \mathrm{s}^{-1}$ at $h=500 \mathrm{~km}$ for a pump frequency of $4040 \mathrm{kHz}$, we find that $E_{||}=(10-15) \mathrm{mV} \cdot \mathrm{m}^{-1}$ at the altitude $300 \mathrm{~km}$ and $E_{||}=(20-40) \mathrm{mV} \cdot \mathrm{m}^{-1}$ at the altitude $500 \mathrm{~km}$.

Summarizing the results of the calculations, one can distinguish the following: (1) the hydrodynamical equilibrium has been disrupted due to the effects of HF pumping into the nightside auroral ionosphere; (2) the partial pressure of ionospheric plasma is about four times higher during the substorm onset than the background level just before the HF heater was turned on; (3) the parallel electric field can reach the values of the order of $E_{\|}=30 \mathrm{mV} \cdot \mathrm{m}^{-1}$ during the substorm onset at 19:30 UT.

\section{Summary}

We suggest that the results obtained provide evidence that HF pumping into nightside auroral ionosphere along the magnetic field-aligned direction produces a modification of the magnetosphere-ionosphere coupling. It is expected that a local heater-driven current system is formed which, in turn, under certain geophysical conditions may cause triggering of auroral activations.

Distinctive features related to auroral activations in the course of the Troms $\varnothing$ HF pumping experiments are identified. Typical peculiarities observed in all events are the following: (1) the generation of burst-like electromagnetic noise observed in bistatic HF Doppler scatter measurements; (2) a strong increase in the ion temperature $T_{i}$ and the local ionospheric electric field $E_{0}$; (3) modification of the auroral arc and local spiral-like formation. However, some features were observed only when the HF pump wave was reflected from the $F 2$ layer under disturbed magnetic conditions. Only the latter experiment shows evidence of strong $T_{e}$ increases with altitude, especially during the triggering of auroral activation. The generation of the intense upward ion flows, strong enhancement of the electron temperature $T_{e}$ in a wide altitude range (from $200 \mathrm{~km}$ to the upper altitude limit of the EISCAT UHF incoherent scatter radar which was $600 \mathrm{~km}$ during experiment) are also observed in this experiment.

A possible scenario for the substorm triggering due to the excitation of the turbulent Alfvén boundary layer (TABL), or in other words, Alfvén vortex instability (AVI), by an unmodulated HF pump wave in the ionospheric Alfvén resonator (IAR) is considered. In this respect the potentiality of the IAR excitation by an unmodulated HF pump wave is discussed. The comparison between electromagnetic noise enhancement from HF Doppler scatter measurements and $\mathrm{PiC}$ and $\mathrm{PiB}$ types of Pil magnetic pulsations points to an association between them. Taking into account that Alfvén wave energy can be trapped in the IAR causing PiB magnetic pulsations, the appearance of the burst-like noise 
enhancement on the Doppler sonogram and PiB magnetic pulsations can be indicative of ionospheric Alfvén resonator effects. Clearly, further experiments and new theoretical approaches are needed.

The enhanced ionospheric electric field, parallel electric field, and turbulent plasma heating are possible mechanisms for Alfvén wave dissipation in the IAR that leads to the excitation of the TABL. One would expect that the heaterinduced runaway electrons may promote the development of current driven instabilities and the formation of an additional acceleration region at low altitudes $(350-1000 \mathrm{~km})$. The hydrodynamical equilibrium has been disrupted due to effects of HF pumping. The partial pressure is about four times greater during the substorm onset than the background level.

Acknowledgements. We would like to thank the Director and Staff of the EISCAT Scientific Association. EISCAT is an International Association supported by Finland, France, The Federal Republic of Germany, Japan, Sweden, Norway, and the United Kingdom. We thank P. Gamet and S. Buchert for making available plotting routines of EISCAT UHF incoherent scatter data. The work is supported by INTAS, grant 03-51-5583 and by RFBR, grant 04-05-64160, NATO Research programme, grant EST.CLG.978226, and the Royal Swedish Academy of Sciences. The financial support from the Swedish Research Council and Uppsala University is gratefully acknowledged. The authors thank A. Gurevich, V. Sergeev, V. Trakhtengerts, K. Stasiewicz, and B. Isham for useful discussions and helpful comments.

Topical Editor M. Lester thanks a referee for his help in evaluating this paper.

\section{References}

Akasofu, S.-I.: The development of the auroral substorm, Planet. Space Sci., 12, 273-282, 1964.

Baron, M. J. and Wand, R. H.: F region ion temperature enhancements resulting from Joule heating, J. Geophys. Res., 88, 41144118, 1983.

Belyaev, P. P., Bösinger, T., Isaev, S. V., Trakhtengerts, V. Y., and Kangas, J.: First evidence at high latitudes for the ionospheric Alfvén resonator, J. Geophys. Res., 104, 4305-4318, 1999.

Bernhardt, P. A., Duncan, L. M., and Tepley, C. A.: Artificial airglow excited by high-power radio waves, Science, 242, 1022$1027,1988$.

Blagoveshchenskaya, N. F., Kornienko, V. A., Borisova, T. D., Thidé, B., Kosch, M. J., Rietveld, M. T., Mishin, E. V., Luk'yanova, R. Yu., and Troshichev, O. A.: Ionospheric HF pump wave triggering of local auroral activation, J. Geophys. Res., 106, 29071-29089, 2001.

Blagoveshchenskaya, N. F., Kornienko, V. A., Petlenko, A. V., Brekke, A., and Rietveld, M. T.: Geophysical phenomena during an ionospheric modification experiment at Troms $\varnothing$, Ann. Geophys., 16, 1212-1225, 1998a,

SRef-ID: 1432-0576/ag/1998-16-1212.

Blagoveshchenskaya, N. F., Kornienko, V. A., Rietveld, M. T., Thidé, B., Brekke, A., Moskvin, I. V., and Nozdrachev, S.: Stimulated emissions around the second harmonic of Troms $\varnothing$ heater frequency observed by long-distance diagnostic HF tools, Geophys. Res. Lett., 25, 873-876, 1998 b.
Borisova, T. D., Blagoveshchenskaya, N. F., Moskvin, I. V., Rietveld, M. T., Kosch, M. J., and Thidé, B.: Doppler shift simulation of scattered HF signals during the Troms $\varnothing$ HF pumping experiment on 16 February, 1996, Ann. Geophys., 20, 1479-1486, 2002 ,

SRef-ID: 1432-0576/ag/2002-20-1479.

Boström, R. A.: Model of the auroral electrojets, J. Geophys. Res. 69, 4983-4999, 1964.

Brändström, B. U. E., Leyser, T. B., Steen, A., Rietveld, M. T., Gustavsson, B., Aso, T., and Ejiri, M.: Unambiguous evidence of HF pump-enhanced airglow at auroral latitudes, Geophys. Res. Lett., 26, 3561-3564, 1999.

Djuth, F. T., Thidé, B., Ierkic, H. M., and Sulzer, M. P.: Large F region electron-temperature enhancements generated by highpower HF radio waves, Geophys. Res. Lett., 14, 953-956, 1987.

Eglitis, P., Robinson, T. R., Rietveld, M. T., Wright, D. M., and Bond, G. E.: The phase speed of artificial field-aligned irregularities observed by CUTLASS during HF modification of the auroral ionosphere, J. Geophys. Res, 103, 2253-2259, 1998.

Forme, F. R. E. and Fontaine, D.: Enhanced ion acoustic fluctuations and ion outflow, Ann. Geophys., 17, 190-209, 1999,

SRef-ID: 1432-0576/ag/1999-17-190.

Foster, J. C.: Radar observations of magnetosphere - ionosphere coupling at middle and high latitudes, J. Geomag. Geoelectr., 47, 801-812, 1995.

Foster, C., Lester, M., and Davies, J. A.: A statistical study of diurnal, seasonal and solar cycle variations of F-region and topside auroral upflows observed by EISCAT between 1984 and 1996, Ann. Geophys., 16, 1144-1158, 1998,

SRef-ID: 1432-0576/ag/1998-16-1144.

Franz, T. L., Kelley, M. C., and Gurevich, A. V.: Radar backscattering from artificial field-aligned irregularities, Radio Sci., 34 465-475, 1999.

Haerendel, G.: Field-aligned currents in the Earth's magnetosphere, in physics of magnetic flux ropes, Geophys. Monogr. Ser., vol. 58, 539-553, AGU, Washington, D.C., 1990.

Honary, F., Robinson, T. R., Wright, D. M., Stocker, A. J., Rietveld, M. T., and McCrea, I.: First direct observation of the reduced striations at pump frequencies close to the electron gyroharmonics, Ann. Geophys., 17, 1235-1238, 1999,

SRef-ID: 1432-0576/ag/1999-17-1235.

Hunsucker, R. D.: Atmospheric gravity waves generated in the high-latitude ionosphere: a review, Rev. Geophys., 20, 293-315, 1982.

Ginzburg, V. L.: Propagation of electromagnetic waves in plasma (in Russian), Nauka, Moscow, 1967.

Gurevich, A. V.: Nonlinear phenomena in the ionosphere, Springer, New York, 1978.

Gurevich, A. V., Carlson, H., Kelly, M., Hagfors, T., Karashtin, A., and Zybin, K. P.: Nonlinear structuring of the ionosphere modified by powerful radio waves at low latitudes, Phys. Lett. A, 251, 311-321, 1999.

Gurevich, A. V., Carlson, H., and Zybin, K. P.: Nonlinear structuring and southward shift of a strongly heated region in ionospheric modification, Phys. Lett. A, 288, 231-239, 2001.

Isham, B., Kofman, W., Hagfors, T., Nordling, J., Thidé, B., La Hoz, C., and Stubbe, P.: New phenomena observed by EISCAT during an RF ionospheric modification experiment, Radio Sci., 25, 251-262, 1990.

Isham, B., Rietveld, M. T., Hagfors, T., La Hoz, C., Mishin, E., Kofman, W., Leyser, T. B., and van Eyken, A. P.: Aspect angle dependence of HF enhanced incoherent backscatter, Adv. Space 
Res., 24, 1003-1006, 1999.

Jones, T. B., Robinson, T. R., Stubbe, P., and Kopka, H.: Frequency dependence of anomalous absorption caused by high power radio waves, J. Atmos. Terr. Phys., 46, 147-153, 1984.

Kagan, L. M. and Frolov, V. L.: Significance of field-aligned currents for F-region perturbations, J. Atmos. Terr. Phys., 58, 14651474, 1996.

Kamide, Y. and Baumjohann, W.: Magnetosphere-Ionosphere Coupling, Springer-Verlag, New York, 1993.

Kan, J.: On the cause of substorm expansion onset and the processes driving the substorm expansion phase, J. Atmos. Terr. Phys., 55, 979-983, 1993.

Kelley, M. C., Arce, T. L., Salowey, J., Sulzer, M., Armstrong, W. T., Carter, M., and Duncan, L.: Density depletions at the 10-m scale induced by the Arecibo heater, J. Geophys. Res., 100, A9, 17 367-17376, 1995.

Kosch, M. J., Hagfors T., and Nielsen, E.: A new digital all-sky imager experiment for optical auroral studies in conjunction with Scandinavian twin auroral radar experiment, Rev. Sci. Instr., 69, 578-584, 1998.

Kosch, M. J., Rietveld, M. T., Hagfors, T., and Leyser, T. B.: Highlatitude HF-induced airglow displaced equatorwards of the pump beam, Geophys. Res. Lett., 27, 2817-2820, 2000.

Kovtyukh, A. S.: Geocorona of hot plasma, Cosmic Res., Engl. Transl., 39, 527-558, 2001.

Leyser, T. B.: Stimulated electromagnetic emissions by highfrequency electromagnetic pumping of the ionospheric plasma, Space Sci. Rev., 98, 223-328, 2001.

Leyser, T. B., Thidé, B., Derblom, H., Hedberg, A., Lundborg, B., Stubbe, P., and Kopka, H.: Stimulated electromagnetic emission near electron cyclotron harmonics in the ionosphere, Phys. Rev. Lett., 63, 1145-1147, 1989.

Lühr, H., Aylward, A., Buchert, S. C., Pajunpaa, A., Holmboe, T., and Zalewski, S. M.: Westward moving dynamic substorm features observed with the IMAGE magnetometer network and other ground-based instruments, Ann. Geophys., 16, 425-440, 1998 ,

\section{SRef-ID: 1432-0576/ag/1998-16-425.}

Lyons, L. R.: Substorms: Fundamental observational features, distinction from other disturbances, and external triggering, J. Geophys. Res., 101, 13 011-13 025, 1996.

Lysak, R. L.: Electrodynamic coupling of the magnetosphere and ionosphere, Space Sci. Rev., 52, 33-87, 1990.

Lysak, R. L.: Feedback instability of the ionospheric resonant cavity, J. Geophys. Res., 96, 1553-1568, 1991.

Lysak, R. L. and Song, Y.: Dynamic of auroral arc formation during substorms, in Proc. Substorms 4 (ICS 4), vol. 238, 35-40, Kluwer Academic Publishers, Dordrecht, 1998.

Mälkki A. and Lundin, R.: Altitude distributions of upward ion beams and solitary wave structures on the Viking data, Geophys. Res. Lett., 21, 2243-2246, 1994.

Mingaleva, G. I. and Mingalev, V. S.: Response of the convecting high-latitude F layer to a powerful HF wave, Ann. Geophys., 15, 1291-1300, 1997, SRef-ID: 1432-0576/ag/1997-15-1291.

Ogawa, Y., Fujii, R., Buchert, S. C., Nozawa, S., Watanabe, S., and van Eyken, A. P.: Simultaneous EISCAT Svalbard and VHF radar observations of ion upflows at different aspect angles, Geophys. Res. Lett., 27, 81-84, 2000.

Ossakow, S. L. and Chaturvedi, P. K.: Current convective instability in the diffuse aurora, Geophys. Res. Lett., 6, 332-335,1979.

Peria, W. J. and Kelley, M. C.: Convection electric field observa- tions near Arecibo HF heater beam, J. Geophys. Res., 106, 18, 517-524, 2001.

Rietveld, M. T., Isham, B., Kohl, H., La Hoz, C., and Hagfors, T.: Measurements of HF-enhanced plasma and ion lines at EISCAT with high-altitude resolution, J. Geophys. Res., 105, 7429-7439, 2000.

Rietveld, M. T., Kosch, M. J., Blagoveshchenskaya, N. F., Kornienko, V. A., Leyser, T. B., and Yeoman, T. K.: Ionospheric electron heating, aurora and striations induced by powerful HF radio waves at high latitudes: aspect angle dependence, J.Geophys.Res., 108(A4), 1141, doi:10.1029/2002JA009543, 2003.

Rietveld, M. T., Kohl, H., Kopka, H., and Stubbe, P.: Introduction to ionospheric heating at Troms $\varnothing$, I. Experimental overview, J. Atmos. Terr. Phys., 55, 577-599, 1993.

Rishbeth, H. and van Eyken, T.: EISCAT: Early history and the first ten years of operation, J. Atmos. Terr. Phys., 55, 525-542, 1993.

Robinson, T. R., Stocker, A., Bond, G., Eglitis, P., Wright, P., Jones, T. B., and Rietveld, M. T.: First CUTLASS-EISCAT heating results, Adv. Space Res., 21, 5, 663-666, 1998.

Robinson, T. R., Strangeway, R., Wright, D. M., Davies, J. A., Horne, R. B., Yeoman, T. K., Stocker, A. J., Lester, M., Rietveld, M. T., Mann, I. R., Carlson, C. W., and McFadden, J. P.: FAST observations of ULF waves injected into the magnetosphere by means of modulated RF heating of the auroral electrojet, Geophys. Res. Lett., 27, 19, 3165-3168, 2000.

Rostoker, G.: The evolving concept of a magnetospheric substorm, J. Atmos. Terr. Phys., 61, 85-100, 1999.

Sagawa, E. I., Iwamoto, I., Watanabe, S., Whalen, B. A., Yau, A W., and Fukunishi, H.: Low energy upflowing ion events observed by EXOS-D: Initial results, Geophys. Res. Lett., 18, $337-$ 340, 1991.

Sergeev, V. A., Pulkkinen, T. I., and Pellinen, R. J.: Coupled-mode scenario for the magnetospheric dynamics, J. Geophys. Res. 101, 13 047-13 065, 1996.

Stasiewicz, K., Lundin, R., and Marklund, G.: Stochastic ion heating by orbit chaotization on electrostatic waves and nonlinear structures, Physica Scripta, T84, 60-63, 2000.

Stasiewicz, K., Bellan, P., Chaston, C., Kletzing, C., et al.: Small scale Alfvénic structure in the aurora, Space Sci. Rev., 92, 423533, 2000

Stubbe, P.: Review of ionospheric modification experiments at Troms $\varnothing$, J. Atmos. Terr. Phys., 58, 349-368, 1996.

Thidé, B., Hedberg, A., Fejer, J. A., and Sulzer, M. P.: First observations of stimulated electromagnetic emissions at Arecibo, Geophys. Res.Lett., 16, 369-372, 1989.

Thidé, B., Derblom, H., Hedberg, A., Kopka, H., and Stubbe, P. Observations of stimulated electromagnetic emissions in ionospheric heating experiments, Radio Sci., 18, 851-859, 1983.

Thidé, B., Kopka, H., and Stubbe, P.: Observations of stimulated scattering of a strong high-frequency radio wave in the ionosphere, Phys. Rev. Lett., 49, 1561-1563, 1982.

Trakhtengerts, V. Y., Belyaev, P. P., Polyakov, S. V., Demekhov, A G., and Bösinger, T.: Excitation of Alfvén waves and vortices in the ionospheric Alfvén resonator by modulated powerful radio waves., J. Atmos. Terr. Phys., 62, 267-276, 2000.

Trakhtengerts, V. Y. and Feldstein, A. Y.: Turbulent Alfvén boundary layer in the polar ionosphere, 1. Excitation conditions and energetics, J. Geophys. Res., 96, 19363-19372, 1991.

Troshichev, O. A., Andresen, V. G., Vennerström, S., and FriisChristensen, E.: Magnetic activity in the Polar Cap - a new index, Planet. Space Sci., 36, 1095-1103, 1988. 
Vas'kov, V. V., Dimant, Ya. S., and Ryabova, N. A.: Magnetospheric plasma thermal perturbations induced by resonant heating of ionospheric F-region by high-power radio wave, Adv. Space Res., 13, 25-33, 1993.

Wahlund, J.-E., Opgenoorth, H. J., Häggström, I., Winsler, K. J., and Jones, G. O. L.: EISCAT observations of topside ionospheric ion outflows during auroral activity: revisited, J. Geophys. Res., 97, 3019-3037, 1992.
Yampolski, Y. M.: Reverberative scattering on artificial ionospheric turbulence, Izv. Vuzov (Radiofizika and Quantum Electronics, in Russian), 32, 519-521, 1989.

Yeoman, T. K., Wright, D. M., Robinson, T. R., Davies, J. A., and Rietveld, M. T.: High spatial and temporal resolution observations of an impulse-driven field line resonance in radar backscatter artificially generated with the Troms $\varnothing$ heater, Ann. Geophys., 15, 634-644, 1997,

SRef-ID: 1432-0576/ag/1997-15-634. 